\title{
Ultrasonography Assessment of Diaphragm in Asthmatic Children and Effects of Diaphragm Strengthening Exercise on Angiogenin Level and Pulmonary Functions
}

\author{
Eman M Fouda ${ }^{1}$, Mahitab Morsy ${ }^{1}$, Safaa K. Mohamed ${ }^{2}$, Ahmed. M. El-Kahky ${ }^{3}$ and Manal A Al Azziz ${ }^{4 *}$ \\ ${ }^{1}$ Department of Pediatrics, Faculty of Medicine, Ain Shams University, Egypt \\ ${ }^{2}$ Department of Radiodiagnosis, Ain Shams University, Egypt \\ ${ }^{3}$ Department of Physical therapy, Ain Shams University, Egypt \\ ${ }^{4}$ Department of Clinical Pathology, Ain Shams University, Egypt \\ Submission:February 15, 2017; Published: May 31, 2017 \\ *Corresponding author: Manal A. al azziz, Department of Clinical Pathology, Ain Shams University, Cairo, Egypt; Email: foudaeman@gmail.com
}

Abstract

Objective: The study aimed at assessment of diaphragmatic thickness, excursion and fatigue in asthmatic children with various clinical and functional grading and also to assess the effect of a specific training program for the diaphragm "diaphragm strengthening exercise" on pulmonary functions and diaphragm ultrasonography.

Methods: It included 45 asthmatic children and 12 healthy children as control group. For all cases, assessment of clinical severity and control according to GINA guidelines (2015), spirometric pulmonary functions and serum angiogenin level as an inflammatory marker were done. sEMG was measured before and after maximum voluntary ventilation (MVV) maneuver to determine the extent of diaphragm fatigue. Diaphragm was assessed by ultrasonography for thickness and excursion. The patients started a special program of "Diaphragm strengthening exercise" by abdominal weights" for 10-12 weeks, twice per week, then they were re-assessed by spirometric pulmonary functions and diaphragm ultrasonography.

Results: This study showed a statistical significant decrease in thickness of diaphragm in asthmatic children $(9.28 \pm 1.88 \mathrm{~mm})$ Vs $(10.4 \pm 1.31 \mathrm{~mm}$ in control) and decreased excursion of diaphragm $(11.06 \pm 3.82 \mathrm{~mm})$ Vs $(12.05 \pm 2.23 \mathrm{~mm}$ in control) $(\mathrm{p}<0.05)$ with marked impairment of diaphragmatic excursion in uncontrolled asthmatics compared to both controlled and partly controlled patients. Serum Angiogenin level was significantly higher in asthmatics and it was inversely correlated to FEV1 and to diaphragmatic thickness and excursion. sEMG recording parameters of diaphragm, including amplitude and frequency were significantly decreased after maximal voluntary ventilation maneuver (decrease of $18 \%$ and $12 \%$ from baseline, respectively), which indicated diaphragmatic fatigue. Reassessment of asthmatic children after short term exercise training for the diaphragm showed significant increase in spirometric pulmonary functions, significant increase in diaphragmatic thickness and diaphragmatic excursion compared to pre-exercise measurements.

Conclusion: diaphragmatic thickness and excursion are affected in asthmatics and it is correlated to pulmonary functions and to inflammatory markers. Diaphragmatic training programs may be of value in improving symptoms and severity of patients with asthma through its effect on diaphragmatic thickness and excursion.

Abbreviations: FEV1: Forced Expiratory Volume in the First Second; FVC: Forced Vital Capacity;, PEF: Peak Expiratory Flow; MVV: Maximum Voluntary Ventilation; FEF25-75\%: Forced Expiratory Flow Rate Over 25-75\% Part of FVC; DSE: Diaphragm Strengthening Exercise: sEMG: Surface Electromyogram; RMS: Root Mean Square

\section{Introduction}

The abnormality of respiratory muscle functions in patients with respiratory diseases is multifaceted. Diaphragm is the inspiratory muscle most shortened during

hyperinflation which is an inevi Table consequence of severe obstructive airway diseases [1]. In asthmatic patients, inspiratory muscles are, forced with an increased load. Air flow obstruction increases resistive work and creates a threshold 
load that needs to be overcomed with each breath. An important goal in managing asthmatic patients should be the reduction of symptoms especially dyspnea. As respiratory muscle function is frequently compromised in those patients and it may contribute to sensation of breathlessness, assessment of their functions are of clinical importance [2].

Several mechanisms contribute to imbalance between respiratory load and capacity with consequent respiratory muscle dysfunction [3]. Although the load on the respiratory system is well-known to be increased in acute asthma, ventilatory failure also might result from the failure of the respiratory muscle pump to generate an adequate negative intrathoracic pressure. Hyperinflation that accompanies airway diseases interferes with the ability of the respiratory muscles to generate subatmospheric pressure and it increases the load on the respiratory muscles [4].

Different inflammatory markers in asthma can decrease diaphragmatic contractility by inducing production of reactive oxygen species which can cause oxidative damage to the regulatory proteins of sarcoplasma and myofilaments [5]. Angiogenin is an inflammatory marker thought to contribute to irreversible airway obstruction via formation of new vessels and the remodeling of the existing vessels [6]. Angiogenin plays a role in a number of vasculo-proliferative pathologic conditions. It has been implicated as a mitogen for vascular endothelial cells, an immune modulator with suppressive effects on polymorph nuclear leukocytes, an activator of certain protease cascades, as well as an adhesion molecule [7].

Short term exercise training for the diaphragm has been found to improve physical fitness and to result in a decrease in number of asthma attacks, emergency room visits, hospitalization and days of absence from school. Also a significant improvement in lung function values and in asthma symptoms may occur [8].

\section{Aim of the work}

The aim of this work was to study the changes in diaphragm as the main inspiratory muscle in asthmatic children with various clinical and functional severity, also to correlate these changes with asthma control, spirometric pulmonary functions, and angiogenin level as an inflammatory marker. The effect of a specific training program for the diaphragm "diaphragm strengthening exercise" on pulmonary functions and diaphragm ultrasonography was also evaluated.

\section{Patients and Methods}

This study was conducted on 45 asthmatic children. They were recruited from the Pediatric Chest Clinic, Ain Shams University Hospital (23 male and 22 female children); their mean age was $9.44 \pm 2.71$ years and mean duration of illness was $6.1 \pm 3.08$ years. Diagnosis of asthma was made according to the criteria approved by American Thoracic Society [9]. Following Global Initiative for Asthma classification [10], asthmatics were classified according to control of asthma into:
Controlled patients $(n=20), 10$ males and 10 females, their ages ranged from 5-15 years with a mean of 9.37 \pm 3.57 years.

Partly controlled patients $(n=15), 9$ males and 6 females, their ages ranged from 7-15 years with a mean of $10.6 \pm 2.79$ years.

Uncontrolled patients $(n=10) 4$ males and 6 females, their ages ranged from 10-15 years with a mean of $12.4 \pm 1.95$ years.

All children were in a Table 1 phase of the disease and did not suffer from respiratory infections for at least 1 month before the measurements. Asthmatic children used inhaled corticosteroids 200 to $400 \mu \mathrm{g}$ twice a day and bronchodilator therapy on demand. None of the cases were on oral corticosteroids.

Patients with other systemic diseases or who were unable to perform reproducible lung function maneuvers were excluded from the study. Twelve age and sex matched healthy children were considered as a control group.

All studied children completed the following:

a. Full history taking and thorough clinical examination.

b. Chest radiography (poster anterior).

c. Pulmonary function testing using spirometry (Med Graphics 1070 series 2E/1085; Medical Graphics; St. Paul, $\mathrm{MN})$. The measured parameters are:

I. FVC (liter) :forced vital capacity .

II. FEV1 (liter): Forced expiratory volume in the first second.

III. -PEF(liter):peak expiratory flow

IV. FEF25-75\% (liter/second):Forced expiratory flow rate over $25-75 \%$ part of FVC.

d. Maximal Voluntary Ventilation (MVV)measurement

When the MVV was measured, the patients were asked to sit up very straight and make sure nothing was restricting chest movement or airflow. The subjects began the test by breathing normally through the mouthpiece, followed by breathing as deeply (recommended depth: 1/2-3/4 of the patient's vital capacity) and rapidly (recommended rate: 70 breaths/min) as possible for 15 seconds At the end of the measurement interval, they were told to resume normal breathing and the mouthpiece was removed [9].

e. Surface EMG recordings for diaphragm [2]

sEMG was measured before and after MVV maneuver to determine the extent of diaphragm fatigue. Surface recordings of the right costal diaphragmatic EMG activity were obtained by using pairs of skin-taped silver/silver chloride electrodes filled with conductive paste. The electrodes were placed in the seventh or eighth intercostal space on the right side of the body at the mid-clavicular line. 
A ground electrode was placed on the sternum. The distance between the two electrodes of a given pair was kept to a minimum, never exceeding $2 \mathrm{~cm}$, and care was taken to place the electrodes in the same orientation as the muscle fibers. Once the electrodes were positioned and a clear EMG signal was confirmed (by a deep inspiration), the electrodes were fixed in place. The influence of the ECG on the EMG signal was minimized by recording from the right side of the body and measurements were done from the segments between QRS complexes. The following parameters were measured during sEMG:

- Root mean square (RMS) $(\mu \mathrm{V})$.

- Median frequency of the EMG power spectrum (Hz).

Both parameters used to diagnose fatigue of diaphragm.

f. Human Angiogenin in the serum

This was performed using a Quantikine ELISA kit (R\&D Systems; Minneapolis, MN). This kit is used for the quantitative determination of human angiogenin. A monoclonal antibody specific for angiogenin has been percolated onto a micro plate. After washing away any unbound substances, an enzyme-linked polyclonal antibody specific for angiogenin is added to the wells. A substrate solution is added to the wells and color develops in proportion to the amount of angiogenin bound. The intensity of color is measured [11].

Ultrasonographic assessment of diaphragmatic thickness by high frequency probes (5-7.5M HZ) to observe diaphragm at zone of apposition which is the part of diaphragm in contact with lateral chest wall below the inferior border of costophrenic angle. The transducer is aligned parallel to midline, then a picture of liver and diaphragm is taken in full inspiration and in full expiration from same point. A line is drawn between the angle of the picture and the dome of diaphragm in both sides in full inspiration and full expiration. The difference between both points is considered the diaphragmatic excursion [12].
The patients started "Diaphragm strengthening exercise" by abdominal weights" for 10-12 weeks, twice per week, then they were re-assessed by Pulmonary function tests and diaphragm ultrasound.

\section{Diaphragm strengthening exercise}

This exercise was done through abdominal weights in Crock-lying position. The abdominal weights are sand weights connected to the upper abdomen with adhesive straps to be applied firmly, their weights were graduated from half kilogram till three kilograms according to patient's ability. The exercise was applied as 2 sessions per week for about 3 months each session takes about 30 minutes while the patient asked to inspire deeply 3 times each minute.

\section{Statistical analysis}

A standard computer program (SPSS for Windows, Release 10.0; SPSS; Chicago, IL) was used for data entry and analysis. All numeric variables were expressed as mean \pm SD. Comparison of different variables in various groups was done using Studentt- test and Mann Whitney test for normal and nonparametric variables, respectively. Comparisons of multiple subgroups were done using analysis of variance and Kruskall-Wallis tests for normal and nonparametric variables, respectively. Pearson and Spearman correlation test were used for correlating normal and nonparametric variables, respectively. For all tests, $\mathrm{p}<0.05$ was considered significant.

\section{Results}

The results of this work were shown in Tables 1-8 and Figures 1-5. There was a statistical significant difference between asthmatic subgroups (controlled, partly controlled and uncontrolled cases) as regards the absolute eosinophilic count, but there is no statistical significant difference between them regarding the clinical parameters and TLC/m3 (Table 1). There was a statistical significant difference between the three subgroups as regards spirometric pulmonary functions tests with lower values in uncontrolled patients (Table 2).

Table 1: Statistical comparison between asthmatic subgroups as regards clinical parameters and some laboratory parameters.

\begin{tabular}{|c|c|c|c|c|c|c|}
\hline Variable & $\begin{array}{c}\text { Controlled } \\
\text { Patients } \\
\text { n=20 }\end{array}$ & $\begin{array}{c}\begin{array}{c}\text { Partly Controlled } \\
\text { Patients } \\
\mathbf{n}=15\end{array}\end{array}$ & $\begin{array}{l}\text { Uncontrolled } \\
\text { Patients } \\
\mathbf{n = 1 0}\end{array}$ & $\mathbf{F}$ & $\mathbf{P}$ & Sig. \\
\hline Age (years) & $7.21 \pm 2.64$ & $7.25 \pm 2.53$ & $8.40 \pm 2.70$ & 0.37 & $>0.05$ & NS \\
\hline $\begin{array}{l}\text { Age on oneset } \\
\text { (years) }\end{array}$ & $2.50 \pm 0.86$ & $2.00 \pm 1.03$ & $2.50 \pm 1.00$ & 0.63 & $>0.05$ & NS \\
\hline $\begin{array}{l}\text { Duration of illness } \\
\text { (year) }\end{array}$ & $4.71 \pm 2.15$ & $5.25 \pm 1.66$ & $5.90 \pm 2.01$ & 0.54 & $>0.05$ & NS \\
\hline $\mathrm{TLC} / \mathrm{m}^{3}$ & $9.05 \pm 3.09$ & $8.22 \pm 2.34$ & $8.86 \pm 4.58$ & 0.13 & $>0.05$ & NS \\
\hline $\begin{array}{c}\text { Absolute } \\
\text { eosinophils } / \mathrm{m}^{3}\end{array}$ & $271 \pm 138$ & $412 \pm 210$ & $540 \pm 230$ & 2.87 & $<0.05$ & S \\
\hline
\end{tabular}




\section{International Journal of Pulmonary \& Respiratory Sciences}

Table 2: Statistical comparison between asthmatic subgroups as regards spirometric pulmonary function tests.

\begin{tabular}{|c|c|c|c|c|c|c|}
\hline $\begin{array}{c}\text { Pulmonary } \\
\text { function } \\
\text { \% of predicted }\end{array}$ & $\begin{array}{c}\text { Controlled } \\
\text { patients } \\
\mathbf{n = 2 0}\end{array}$ & $\begin{array}{c}\text { Partly controlled } \\
\text { patients } \\
\mathbf{n = 1 5}\end{array}$ & $\begin{array}{c}\text { Uncontrolled } \\
\text { patients }\end{array}$ & F & P & Sig \\
\hline FEV1 & $<0.001$ & 29.99 & $41.20 \pm 12.28$ & $64.38 \pm 4.20$ & $81.29 \pm 7.69$ & HS \\
\hline FVC & $<0.001$ & 26.24 & $53.40 \pm 12.24$ & $73.62 \pm 6.23$ & $86.57 \pm 5.32$ & HS \\
\hline FEF25-75\% & $<0.05$ & 3.21 & $36.80 \pm 14.72$ & $62.50 \pm 25.93$ & $72.29 \pm 27.22$ & S \\
\hline PEF & $<0.05$ & 22.5 & $62 \pm 8.7$ & $75 \pm 7.35$ & $81.69 \pm 11.12$ & S \\
\hline MVV & $<0.05$ & 14.3 & $52 \pm 7.3$ & $56 \pm 8.4$ & $60.41 \pm 10.7$ & S \\
\hline
\end{tabular}

There was a statistical significant lower values of diaphragmatic thickness and excursion in asthmatics compared to control. (Table 3 and Figure 1). There was a statistical significant positive correlation between pulmonary functions and diaphragmatic thickness and excursion in asthmatics (Table 4). Angiogenin level was significantly higher in asthmatic children compared to control and was significantly higher in uncontrolled cases compared to controlled and partly controlled cases (Table 5 and Figure 2).

Table 3: Statistical comparison between asthmatics and control groups as regards ultrasonographic assessment of diaphragmatic thickness and excursion.

\begin{tabular}{|c|c|c|c|c|}
\hline $\begin{array}{c}\text { Pulmonary Function } \\
\text { Tests }\end{array}$ & \multicolumn{2}{|c|}{$\begin{array}{c}\text { Diaphragmatic } \\
\text { Thickness }\end{array}$} & \multicolumn{2}{c|}{$\begin{array}{c}\text { Diaphragmatic } \\
\text { Excursion }\end{array}$} \\
\cline { 2 - 5 } (\% of predicted) & $\mathbf{r}$ & $\mathbf{P}$ & $\mathbf{r}$ & $\mathbf{P}$ \\
\hline FEV1 & -1.13 & $\begin{array}{c}<0.05 \\
(\mathrm{~S})\end{array}$ & -1.16 & $<0.05(\mathrm{~S})$ \\
\hline PEF & -1.07 & $\begin{array}{c}<0.05 \\
(\mathrm{~S})\end{array}$ & -1.34 & $<0.05(\mathrm{~S})$ \\
\hline
\end{tabular}

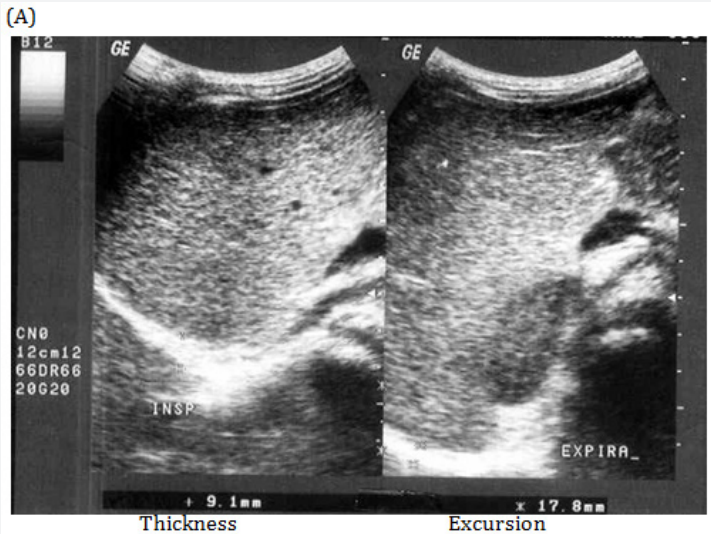

(B)

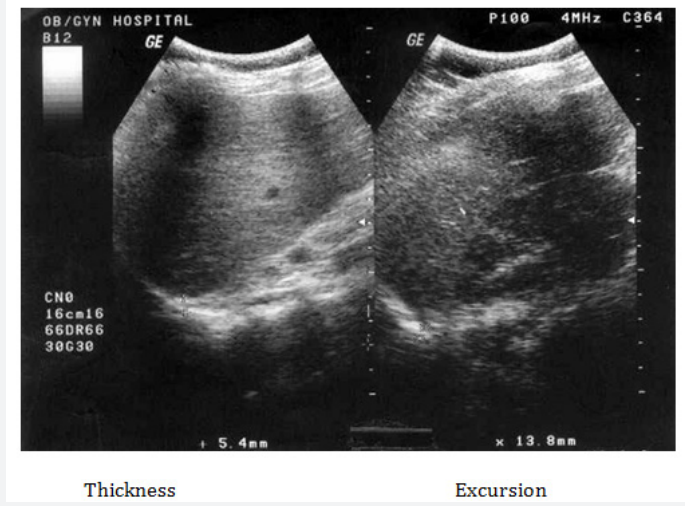

Figure 1: Example of ultrasonography of the diaphragm for assessment of its thickness and excursion in control (A) and asthmatic children (B).

Table 4:Statistical Correlation between some parameters of pulmonary function tests and diaphragmatic thickness and excursion in bronchial asthma.

\begin{tabular}{|c|c|c|c|c|}
\hline $\begin{array}{c}\text { Pulmonary } \\
\text { Function } \\
\text { Tests } \\
\text { (\% of } \\
\text { predicted) }\end{array}$ & \multicolumn{2}{|c|}{$\begin{array}{c}\text { Diaphragmatic } \\
\text { Thickness }\end{array}$} & $\begin{array}{c}\text { Diaphragmatic } \\
\text { Excursion }\end{array}$ & $\begin{array}{c}\text { Diaphragmatic } \\
\text { Excursion }\end{array}$ \\
\cline { 2 - 5 } & $\mathbf{P}$ & $\mathbf{P}$ & $\mathbf{P}$ \\
\hline FEV1 & -1.13 & $\begin{array}{c}<0.05 \\
(\mathrm{~S})\end{array}$ & -1.16 & $<0.05(\mathrm{~S})$ \\
\hline PEF & -1.07 & $\begin{array}{c}<0.05 \\
(\mathrm{~S})\end{array}$ & -1.34 & $<0.05(\mathrm{~S})$ \\
\hline
\end{tabular}

sEMG recording parameters of diaphragm, including amplitude and frequency, were significantly decreased after maximum voluntary ventilation maneuvers (decrease of $18 \%$ and $12 \%$ from baseline, respectively), $\mathrm{P}<0.05$ (Table 6). After Diaphragm strengthening exercise (DSE), a statistical significant higher values of FEV1, FVC, FEV/FVC, PEF, FEF25-75\% and MVV were detected compared to pre-exercise levels (Table 7). There was an increase in both thickness and excursion after Diaphragm strengthening exercise in asthmatic patients (Table 8 and Figure 5).

Table 5: Statistical comparison between asthmatic patients and control groups as regards serum angiogenin level.

\begin{tabular}{|c|c|c|c|c|}
\hline & $\begin{array}{c}\text { Asthmatic } \\
\text { Group } \\
\mathbf{n = 4 5}\end{array}$ & Control n=12 & $\mathbf{t}$ & $\mathbf{p}$ \\
\hline $\begin{array}{c}\text { Angiogenin } \\
\text { level }\end{array}$ & $5717.7 \pm 1682.2$ & $1599 \pm 497.6$ & 7.59 & $<0.05(\mathrm{~S})$ \\
\hline
\end{tabular}




\section{International Journal of Pulmonary \& Respiratory Sciences}

Table 6: Surface EMG parameters of diaphragm before and after maximum voluntary ventilation (MVV) maneuver.

\begin{tabular}{|c|c|c|c|c|}
\hline \multirow{2}{*}{ Surface EMG parameter } & \multicolumn{2}{|c|}{ Asthmatics N=45 } & Control N=12 \\
\hline & Before MVV & After MVV & Before MVV & After MVV \\
\hline RMS of amplitude $(\mu \mathrm{V})$ & $58.5 \pm 13.2$ & $47.9 \pm 12.1$ & $60.2 \pm 12.9$ & $103.2 \pm 17.5$ \\
\hline Median frequency (Hz) & $101.8 \pm 16.2$ & $89.7 \pm 14.4$ & $104.0 \pm 17.0$ & 0.34 \\
\hline R & \multicolumn{2}{|c|}{1.65} & $>0.05(\mathrm{NS})$ \\
\hline P & $<0.05(\mathrm{~S})$ & & \\
\hline
\end{tabular}

Table 7: Statistical comparison between asthmatic group before and after Diaphragm strengthening exercise as regards spirometric pulmonary function tests.

\begin{tabular}{|c|c|c|c|c|}
\hline $\begin{array}{c}\text { Pulmonary Function \% } \\
\text { of Predicted }\end{array}$ & Before DSE & After DSE & t & P \\
\hline FEV1 & $79.31 \pm 6.63$ & $85.94 \pm 6.32$ & 5.65 & $<0.01(\mathrm{HS})$ \\
\hline FVC & $83 \pm 12.31$ & $86.69 \pm 5.72$ & 1.64 & $>0.05$ (NS) \\
\hline FEV1/FVC & $92.25 \pm 14.32$ & $99.13 \pm 4.08$ & 1.98 & $<0.05$ (S) \\
\hline PEF & $62 \pm 18.58$ & $78.06 \pm 14.74$ & 5.44 & $<0.01$ (HS) \\
\hline FEF25-75\% & $65.5 \pm 19.19$ & $80.19 \pm 14.89$ & 4.96 & $<0.01(\mathrm{HS})$ \\
\hline MVV & $60.41 \pm 10.7$ & $82.41 \pm 8.7$ & 3.37 & $<0.01(\mathrm{HS})$ \\
\hline
\end{tabular}

Table 8: Statistical comparison between diaphragm thickness and motility (excursion) in asthmatics before and after Diaphragm strengthening exercise.

\begin{tabular}{|c|c|c|c|c|}
\hline $\begin{array}{c}\text { Diaphragmatic } \\
\text { Ultrasound }\end{array}$ & $\begin{array}{c}\text { Before Diaphragm } \\
\text { strengthening exercise }\end{array}$ & $\begin{array}{c}\text { After Diaphragm } \\
\text { strengthening exercise }\end{array}$ & $\mathbf{t}$ & $\mathbf{P}$ \\
\hline $\begin{array}{c}\text { Diaphragmatic thickness } \\
(\mathrm{mm})\end{array}$ & $9.28 \pm 1.88$ & $10.2 \pm 1.97$ & 1.68 & $<0.05(\mathrm{~S})$ \\
\hline $\begin{array}{c}\text { Diaphragmatic excursion } \\
(\mathrm{mm})\end{array}$ & $11.06 \pm 3.82$ & $11.92 \pm 3.55$ & 1.98 & $<0.05(\mathrm{~S})$ \\
\hline
\end{tabular}

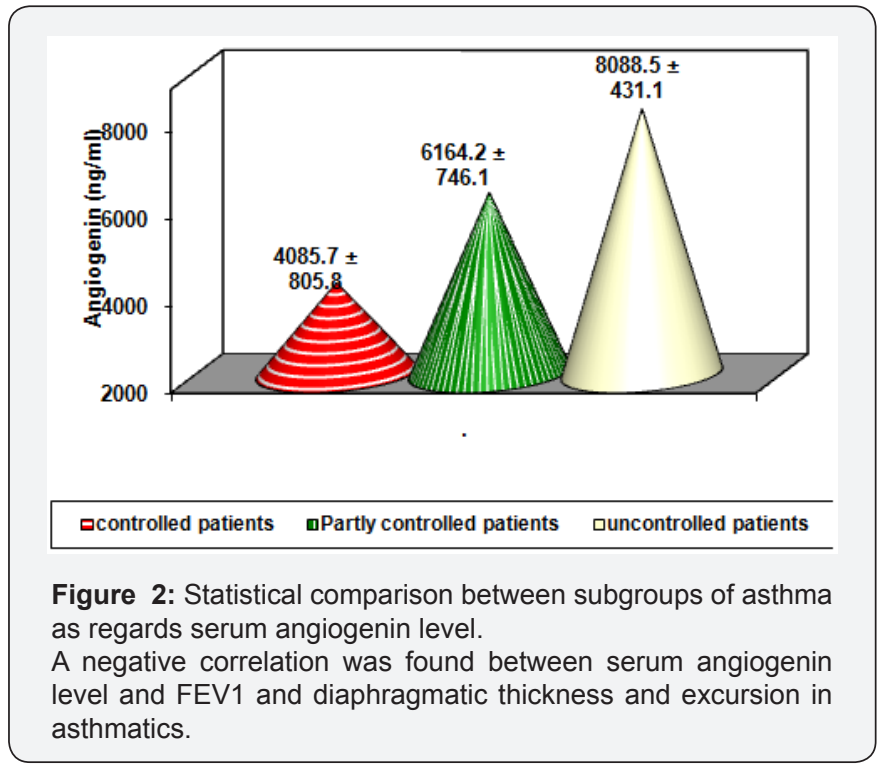

\section{Discussion}

This study revealed a statistical significant decreased thickness of the diaphragm in asthmatic patients $(9.28 \pm 1.88 \mathrm{~mm})$ compared to control group $(10.4 \pm 1.31 \mathrm{~mm}) \quad(\mathrm{P}<0.05)$, and less diaphragmatic excursion "motion" in asthmatics $(11.06 \pm 3.82 \mathrm{~mm})$ compared to control $(12.05 \pm 2.23 \mathrm{~mm})$ $(\mathrm{p}<0.05)$. This was in accordance with Targhette [12] who evaluated diaphragmatic excursion and thickness in asthmatic children by ultrasonography. They revealed a statistical significant decreased thickness and less excursion of diaphragm in asthmatics compared to control. De Bruin [13] recorded decreased thickness of diaphragm in patients with obstructive airway disease when assessed by ultrasound. They explained this finding by a significant increase in the number of type I fibers (slow twitch) which has the smallest cross sectional area and decrease in type II (fast twitch) fibers which has the largest cross sectional area. This fast to slow twitch fiber transition in the diaphragm can be regarded as an advantageous adaptation as it will attenuate fatigability of the diaphragm.

Several studies have been reported on the effect of airway obstruction on diaphragmatic functions [14-20]. However, hyperinflation was proved by many workers to be the main underlying etiology. Hyperinflation forces the diaphragm to operate in an inefficient way for its force-length relationship. This will decrease the ability of the diaphragm to generate negative pressure during inspiration. Also hyperinflation 


\section{International Journal of Pulmonary \& Respiratory Sciences}

causes flattening of the diaphragm which in turn places it in a serious mechanical disadvantage being curved upward, so decreased excursion [12]. Hyperinflation also leads to loss of axial direction of diaphragmatic fibers and become directed medially or inwards [4]. Also as the contractile force increase in order to develop the inspiratory pressure necessary to inflate hyperinflated lungs, the diaphragm blood supply may be altered affecting its thickness and excursion [4].

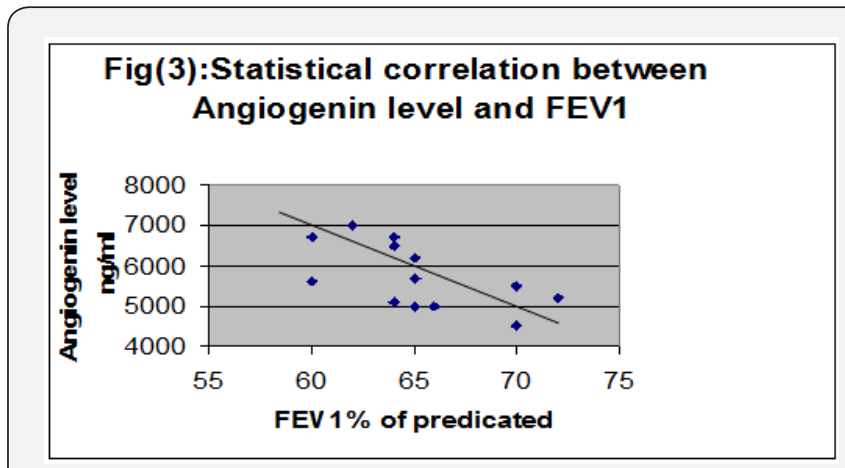

Figure 3: Statistical correlation between angiogenin levels and FEV1( percentage of predicted) in asthmatic patients.

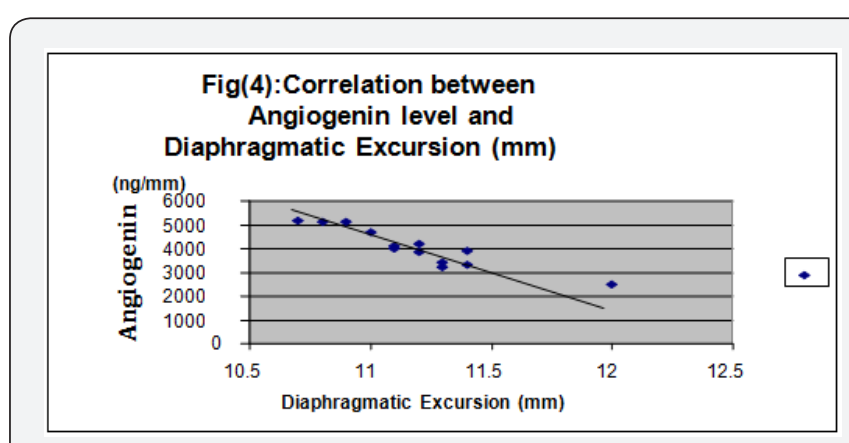

Figure 4: Statistical correlation between angiogenin levels and Diaphragmatic excursion in asthmatic patients.

Andrade [14] stated that overproduction of free radicals which is commonly accompany inflammation in bronchial asthma is associated with impaired contractile performance, reduce calcium sensitivity of the diaphragm and increase fatigue rate. Reid [5] stated that asthmatic patients have increased plasma levels of tumor necrosis factor- alpha, which decreases diaphragmatic strength through several mechanisms as decreased muscle anabolism, increased muscle catabolism and inhibition of contractility. Weiner [15] concluded that increasing energy cost of breathing combined with possible impaired function of the respiratory muscles due to multiple factors as hyperinflation, acute and chronic steroid myopathy, malnutrition, put patients with asthma at risk of respiratory muscle impairment mainly diaphragm affecting its thickness and excursion. Spyros [16] stated that asthmatics particularly uncontrolled cases are liable to increase airway expiratory resistance and high ventilatory demand. This lead to development of intrinsic positive end expiratory pressure or auto PEEP. This phenomenon is called dynamic hyperinflation which has its direct effect on diaphragmatic excursion and activity.
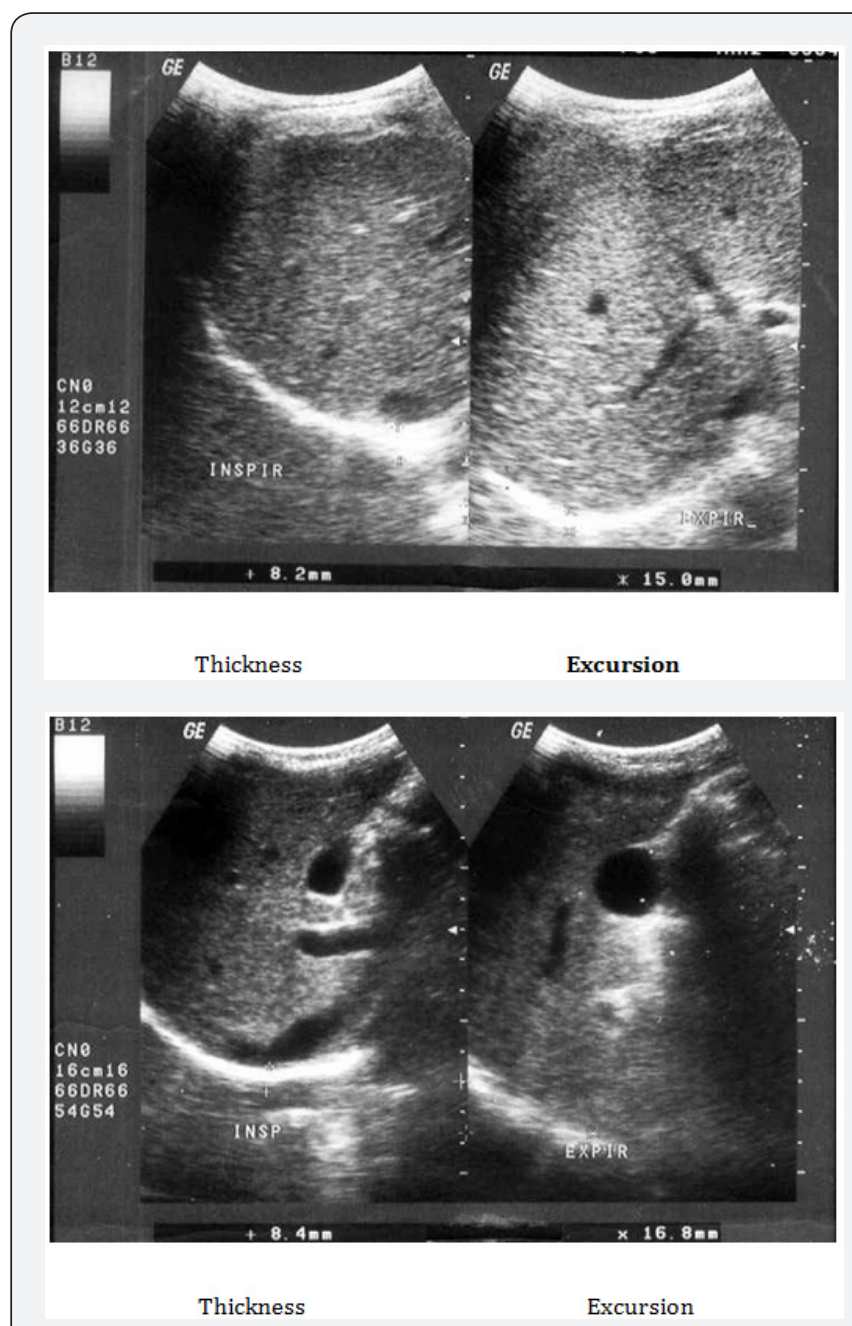

Figure 5: Ultrasonography of the diaphragm of a female child, aged 9 years old with partly uncontrolled asthma (A) Picture obtained before DSE diaphragm thickness $=8.2 \mathrm{~mm}$, diaphragm excursion $=15 \mathrm{~mm}$. (B) After DSE diaphragm thickness $=8.4 \mathrm{~mm}$ , diaphragm excursion $=16.8 \mathrm{~mm}$.

Inhaled and systemic glucocorticoids which represent the main therapy of patients with asthma although decreasing airway inflammation, it enhance the perception of inspiratory muscle effort during histamine-induced bronchoconstriction [4]. Ottenheijm [1] stated that ultrasound provides a noninvasive assessment of diaphragm thickness and contraction in respiratory diseases particularly if hyperinflation is expected. This work showed a positive correlation between PEFR and FEV1 with diaphragmatic excursion and diaphragmatic thickness $(\mathrm{P}<0.01)$. This was in accordance with [3] who reported a positive correlation between pulmonary functions and changes in diaphragm excursion in asthmatic patients. As severity of airflow obstruction increases, the proportion of abnormal diaphragmatic functions increases. In contrast [17] found no relation between accessory muscle abnormalities and 
pulmonary functions. This difference could be attributed to the possibility that their work assessed external and internal intercostals and diaphragm. The former muscles are believed to be mainly postural muscles that are inactive or minimally active during resting or stimulated breathing. In the current work, the mean level of angiogenin in asthmatic children was significantly higher than healthy children $(\mathrm{p}<0.001)$ This result was in agreement with many authors [1-21] who also hypothesized that angiogenin is considered among the most important factors that contribute to airway hyperesponsiveness by inducing chronic airway remodeling, thus leading to irreversible airway changes in asthma.

A significant negative correlation was found between angiogenin levels and FEV1 (percentage of predicted) and diaphragmatic excursion. In accordance with the above results, Vrugt [22] and Salvato [18] showed that uncontrolled asthmatic cases had more blood vessels in bronchial wall than patients with controlled asthma due to higher levels of angiogenesis factors, which suggests a possible relation between vascular remodeling of the airway wall and asthma severity and control. [19] concluded that patients with uncontrolled asthma display chronic hyperinflation results from fixed airway obstruction (airway remodeling) secondary to vasodilatation of blood vessels in airways. This dynamic hyperinflation increases expiratory flow limitation and impairs pulmonary functions. It also flattens the diaphragm and reduces generation of force since muscle contraction results from a mechanically disadvantageous fiber length. Bronchial vascular remodeling, with an increase in size and number of blood vessels as well as vascular hyperemia have been proposed as contributing factors in airway wall remodeling in patients with uncontrolled asthma [20].

This study showed that sEMG recording parameters, including RMS of amplitude and frequency were significantly decreased after MVV maneuver (decrease of 18\% and 12\% from baseline, respectively, $(\mathrm{P}<0.05)$ in asthmatic children compared to control. These results suggested that the diaphragm is exposed to fatigue in asthmatics after the MVV maneuvers. This was in agreement with other researchers [21,22]. A number of mechanisms may be involved in decreased sEMG amplitude and frequency of diaphragm in asthmatics. It was reported that decrease of sEMG amplitude in the diaphragm might reflect decreased motor unit recruitment due to decreased activation of the target muscles caused by central fatigue [23] or decrease of individual motor unit action potential [24]. The reduction in median frequency of the EMG power spectrum has been typically considered as an indicator of fatigue as it has been noted during fatigue by maximum and sub-maximum voluntary contractions $[21,25]$. The shift in the EMG power spectrum is considered to be associated with fatigue-induced metabolite accumulation, change in intracellular $\mathrm{PH}$, and reduction in muscle fiber conduction velocity. Changes in frequency could also represent the change of the recruitment because previous research reported that the frequency changed as the levels of contractions changes [24]. During quiet breathing, type I fibers of diaphragm are predominately activated. Type II fibers are required in conditions requiring more force generation as during maximal voluntary breathing. Fatigue may result when type II fibers can no longer be effectively activated to sustain the force of contraction. Conventionally, the diaphragm is believed to be a skeletal muscle that does not fatigue easily. Some investigators suggested that MVV maneuvers might not cause the muscle itself to fatigue, but induce the "protective" central fatigue. Because peripheral muscle fatigue would result in persistent muscle fatigue and longer recovery period, perhaps central nerve system would induce an earlier fatigue to prevent further inspiratory muscle fatigue [25].

This study explored the effect of 12 weeks of strengthening exercise of diaphragm in asthmatic children. It revealed a statistical significant higher values of FEV1, FEV1/FVC, PEF and MVV and also a significant increase in diaphragmatic thickness and excursion in asthmatic patients after diaphragm strengthening exercise. Many authors studied the effect of non respiratory exercise on pulmonary function parameters in asthmatic children [19, 21,26-29,] Their results revealed marked improvement in pulmonary functions after diaphragmatic training. Girodo [29] studied the effect of 16-week program of diaphragmatic strengthening exercise for asthmatic patients. They found a significant reduction in medication use and in the intensity of asthmatic symptoms. A follow up at two months found that many patients have returned to earlier medication levels with marked impairment in their PEF. McCool [30] postulated that weight-bearing maneuvers may be used to strengthen the diaphragm and expiratory muscles. However they found that although strength training leads to myofiber hypertrophy, it does not result in mitochondrial proliferation, so weight lifting increases diaphragm structure and pressures with less effect on contractility and excursion.

Al-Bilbesi and McCool [31] confirmed that during weightlifting maneuvers, abdominal pressure is increased and the diaphragm may be tensed to minimize the transmission of intraabdominal pressure to the thorax. Consequently the diaphragm is recruited and trans-diaphragmatic pressure is increased. Weiner [21] studied the effect of specific diaphragm training program in patients with asthma. They resulted in a significant improvement in respiratory muscle performance and a decrease in the sensation of breathlessness with decrease in $\beta 2$-agonist consumption. They explained that by the increased inspiratory muscle strength in trained patients. Ramirez-Sarmiento [8] observed an increase in both the strength and endurance of diaphragm after diaphragm strengthening exercise with an increase in proportion of type I fiber and decrease in type II fibers. In addition both fiber types exhibited an increase in cross-sectional area. They concluded that diaphragm training induces a specific functional improvement of diaphragm and adaptive changes in the structure. 
DePalo et al. [27] measured diaphragm thickness by ultrasound at baseline and 8 and 16 wk after diaphragm strengthening exercise. After training, there was significant increase in diaphragm thickness. They stated that the diaphragm and abdominal muscles can be recruited during diaphragm strengthening maneuvers. With these maneuvers, trans-diaphragmatic pressures are elevated to levels that could potentially provide a strength-training stimulus. Enright [32] and Padula and Yeaw [33] suggested that high-intensity inspiratory muscle training and diaphragm strengthening result in increased contracted diaphragm thickness and increased lung volumes and exercise capacity in patients with obstructive airway diseases.

\section{Conclusion}

In future studies of respiratory muscle function in asthma should be aided by measurement of diaphragm thickness and excursion particularly in patients with severe hyperinflation who are most likely to have impairment of muscle function. Diaphragmatic training programs may be of value in improving pulmonary functions of children with asthma.

sodium alendronate can be easily delivered through inhalation devices. Dendrimers are getting attention as in these days. These are nano-size synthetic macromolecules with a highly branched structure and globular shape. Dendrimers contain a large number of terminal groups, which allows these molecules to bind with several drugs at the same time and can deliver them with accuracy and precision.

There are several dendrimer-based formulations available, such as anticancer drug fluorouracil attached to the dendrimers with cyclic core and antitumor drugs adriamycin and methotrexate with dendrimers having poly(ethylene glycol) grafts. Precision and targeted drug delivery is rapidly gaining importance now a days and considering the mechanical improvement of formulation and delivery devices, nanoparticles and nanoparticles-mediated drug delivery are at the peak. However, since the characteristics of the engineered nanocarriers or nano formulations are complex and may change in certain solutions or devices, $\mathrm{t}$ is important to focus on the development of appropriate devices to deliver the drugs effectively. Preclinical and animal studies are extremely important at this stage to investigate the efficacy and safety of these formulations before bringing them as regular treatment modality.

\section{References}

1. Ottenheijm CA, Jenniskens GJ, Geraedts MC, Hafmans T, Heunks LM, et al. (2007) Diaphragm dysfunction in chronic obstructive pulmonary disease: a role for heparan sulphate? Eur Respir J 30(1): 80-89.

2. Mador MJ, Kufel TJ, Pineda LA, Sharma GK (2000) Diaphragmatic fatigue and high intensity exercise in patients with chronic obstructive pulmonary disease. Am J Respir Crit Care Med 161(1): 118-123.

3. MacGowan NA, Evans KG, Road JD, Ried WD (2001): Diaphragm injury in individuals with airflow obstruction. Am J Respir Crit Care Med 163(7): 1654-1659.
4. Laghi F, Tobin MJ (2003) Disorders of the respiratory muscles. Am J Respir Cri Care Med 168(1): 10-48.

5. Reid MB, Lannergren J, Westerblad H (2002) Respiratory and limb muscle weakness induced by tumor necrosis factor- alpha : involvement of muscle myofilaments. Am J Respir Crit Care Med 166(4): 479484 .

6. Salvato G (2001) Quantitative and morphological analysis of the vascular bed in bronchial biopsy specimens from asthmatic and nonasthmatic subjects. Thorax 56(12): 902-906.

7. Abdel-Rahma AM, El-Sahrigy SA, Bakr SI (2006) A Comparative Study of Two Angiogenic Factors: Vascular Endothelial Growth Factor and Angiogenin in Induced Sputum From Asthmatic Children in Acute Attack. Chest 129(2): 266-271.

8. Ramirez-Sarmiento A, Orozco-Levi M, Guell R, Barreiro E, Hernandez $\mathrm{N}$, et al. (2002) Inspiratory muscle training in patients with chronic obstructive pulmonary disease. Am J Respir Crit Care Med 166(11): 1491-1497.

9. American Thoracic Society (1987) Standards for diagnosis and care of patients with chronic obstructive pulmonary disease (COPD) and asthma. Am Rev Respir Dis 136(1): 225-244.

10. Global Initiative for Asthma (GINA) (2015): Global Strategy for asthma management and prevention.

11. Vrugt B, Wilson S, Bron A, Holgate ST, Djukanovic R, et al. (2000): Bronchial angiogenesis in severe glucocorticoid-dependent asthma. Eur Respir J 15(6): 1014-1021.

12. Targheta R, Chavagneux R, Ayoub J, Lemerre C, Préfaut C, et al. (1995): Right diaphragmatic kinetics measured by TM mode ultrasono-graphic with concomitant spirometry in normal subjects and asthmatic patients. Rev Me Interne 16(11): 819-826.

13.De Bruin PF, Ueki J, Watson A, Pride NB (1997) Size and strength of the respiratory and quadriceps muscles in patients with chronic asthma. Eur Resp J 10(1): 59-64.

14.Andrade FH, Reid MB, Allen DG, Westerblad H (1998) Effect of hydrogen peroxide and dithiothreitol on contractile function of single skeletal muscle fibers from the mouse. J Physiol 509(2): 565-575.

15. Weiner P, Berar-Yanay N, Davidorich A, Magadle R, Weiner M (2000) Specific inspiratory muscle training in patients with mild asthma with high consumption of B2 agonists Chest 117(3): 722-727.

16. Papiris S, Kotanidou A, Malagari K, Roussos C (2002) Clinical review: Severe asthma. Crit Care 6(1): 30-44.

17. Hards JM, Reid WD, Pardy RL, Pare PD (1990) Respiratory muscle fiber morphometry : Correlation with pulmonary function and nutrition. Chest 97(5): 1037-1044.

18.Salvato G (2001) Quantitative and morphological analysis of the vascular bed in bronchial biopsy specimens from asthmatic and nonasthmatic subjects. Thorax 56(12): 902-906.

19. Orozco-Levi M (2003) Structure and function of the respiratory muscles in patients with COPD: impairment or adaptation? Eur Respir J 46: 41S-51S.

20. Baena-Cagnan C, Rossi GA, Canonica GW (2007) Airway Remodeling in Children: When Does it Start? Curr Opin Allergy Clin Immunol 7(2): 196-200.

21. Verges S, Notter D, Spengler CM (2006) Influence of diaphragm and rib cage muscle fatigue on breathing during endurance exercise. Respir Physiol Neurobiol 154(3): 431-442.

22. Vrugt B, Wilson S, Bron A, Holgate ST, Djukanovic R (2000) Bronchial angiogenesis in severe glucocorticoid-dependent asthma. Eur Respir ] 15(6): 1014-1021. 
23. Verin E, Straus C, Demoule A, Mialon P, Derenne J, et al. (1985) Validation of improved recording site to measure phrenic conduction from surface electrodes in humans. J Appl Phsyiol 92(3): 967-974.

24. Weiner P, Berar-Yanay N, Davidorich A, Magadle R, Weiner M (2000) Specific inspiratory muscle training in patients with mild asthma with high consumption of B2 agonists Chest 117(3): 722-727.

25. Wen A, Woo S, Knees TG (1997) How many maneuvers are required to measure maximal inspiratory pressure accurately? Chest 111(3) 802-807.

26. Bisschop A, Gayan, Ramirez G, Rollier H, Gosselink R, Dom R, et al (1997) Intermittent, inspiratory muscle training induces fiber hypertrophy in rat diaphragm. Am J Respir Crit Care Med 155(5): 1583-1589.

27. DePalo VA, Parker AL, Al-Bilbeisi F, McCool FD (2004) Respiratory muscle strength training with non-respiratory maneuvers. Appl Physiol 96(2): 731-734.

28. Ram FS, Robinson SM, Black PN, Picot J, Esterman AJ, et al. (2013) Physical training for asthma. : Cochrane Database Syst Rev (9): CD001116.
29. Girodo M, Ekstrand KA, Metivier GJ (1992): Deep diaphragmatic breathing: Rehabilitation exercises for the asthmatic patients. Arch Phys Med Rehabil 73(8): 717-720.

30. McCool FD, Bendit JO, Conomos P, Anderson L, Sherman CB, et al. (1997): Variability of diaphragm structure among healthy individuals. Am J Respir Crit. Care Med 155(4): 1323-1328.

31. Al-Bilbesi F, McCool F (2000): Diaphragm recruitment during non respiratory activities. Am J Respir Crit Care Med 162(2): 456-459.

32. Enright SJ, Unnithan VB, Heward C, Withnall L, Davies DH (2006) Effect of high-intensity inspiratory muscle training on lung volumes, diaphragm thickness, and exercise capacity in subjects who are healthy. Phys Ther 86(3): 345-354.

33. Padula CA, Yeaw E (2007): Inspiratory muscle training: integrative review of use in conditions other than COPD. Res Theory Nurs Pract 21(2): 98-118.

\begin{tabular}{l} 
Your next submission with Juniper Publishers \\
will reach you the below assets \\
- Quality Editorial service \\
- Swift Peer Review \\
- Reprints availability \\
- E-prints Service \\
- Manuscript Podcast for convenient understanding \\
- Global attainment for your research \\
- Manuscript accessibility in different formats \\
( Pdf, E-pub, Full Text, Audio) \\
- Unceasing customer service \\
Track the below URL for one-step submission \\
https://juniperpublishers.com/online-submission.php \\
\hline
\end{tabular}

